of the Curate's Egg comes frequently to mind while reading it. In the story, a young curate was breakfasting with his bishop, when the superior remarked that the youngster had been given a spoiled egg. The curate, embarrassed by the fuss, continued to eat the bad egg while assuring his bishop that "parts of it are excellent." Luckily, this volume is more compartmentalized than is usual with eggs.

Blessedly few of the chapters read like $\mathrm{Arc} U_{\text {ser }}$ magazine reprints. Many of the authors, however, are clearly not experienced technical writers (as the level of writing in most "scientific" periodicals demonstrates is not uncommon in the field), so a good deal of some chapters are a good deal less clear than they might have been. For example, there seems to be a widespread misunderstanding of the concept of paragraph. Webster's dictionary (1944) defines it as "A distinct section or subdivision of a discourse, chapter, or writing, whether of one or many sentences, that forms a rhetorical unit as dealing with a particular point of the subject, or as comprising the words of a distinct speaker, etc." By contrast, in some of this book's chapters, paragraphs are employed simply as random breaks in the text.

It is worse than that, though. My review copy is filled with penciled corrections, excisions, and rearrangements of material, and not a few question marks. Sadly, some of the most potentially useful chapters, particularly Chapter 2, "Meteorological data in a geodatabase," are almost incoherent. The two authors of Chapter 2 do not so much perform a deep dive into UML and the International $\mathrm{H} 2 \mathrm{O}$
Project (IHOP) database structure as to smack into it fulltilt boogie: the results are awkward, confusing, and downright gory.

One should also say something about the standard Esri Press book layout; in particular, the tremendously long text lines used for body text. These lines are just too long for comfortable reading. Standard good practice tells us that "... even with generous leading, a line that averages more than 75 or 80 characters is likely to be too long for continuous reading" (Bringhurst 2002, 27). Standard Esri Press text lines average about 90 characters. Moving either to a wider page fly space (and narrower text block) or to two columns (maybe a less happy solution) would make reading one of these books rather less of a slog.

So, to wrap up: Mapping and Modeling Weather and Climate with GIS is a good stab at filling a big need. It is not without problems, but what in this vale of tears is not? If your office works with weather and climate modelers, this book should be there too.

\section{REFERENCES}

Bringhurst, Robert. 2002. The Elements of Typographic

Style, Version 2.5. Vancouver: Hartley and Marks.

Webster's New International Dictionary of the English

Language, 2nd Edition. 1944. Springfield, Mass: G\&C

Merriam.

\title{
AMERICAN CAPITALS: A HISTORICAL GEOGRAPHY
}

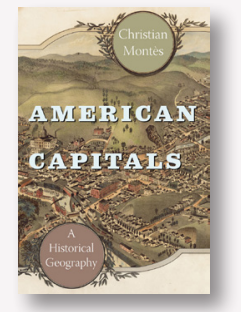

by Christian Montès

University of Chicago Press, 2014

394 pages. \$19.95, softcover.

ISBN: 978-0-226-08048-2

Review by: Russell S. Kirby, University of South Florida

As a peripatetic late twentieth- and early twenty-first-century academic, born to an academic family, my early life and later career led to residence in many US states, and I have had the good fortune to have lived in both large and smaller cities, some of which were state capitals. My professional and personal travels have led to visits to many other state capitals as well. Still, it never occurred to me that the subject of state capitals might be worthy of a book-length historical geographic treatment.

This monograph, published as a University of Chicago Research Paper, shows that it indeed might. In his study, Christian Montès thoroughly explores the topic of the capitals of the states (and territories) of the United States. It could perhaps be said that Montès examines his subject from every conceivable perspective: from the relative locations of capitals within states, to change in location of state capitals over time, to their very names, while also examining a wide array of other questions along the way. 
Montès begins with a discussion of the various roles capitals play as administrative centers and as loci for political and judicial activity, and as "places of memory" in historical, social, and cultural contexts. Additional topics explored in turn include the geography of capital locations from colonial times to the present, an examination of the factors involved in capital choice, and comparative analyses of the demographic and economic characteristics of capital cities prior to and since 1950 . He also applies a conceptual model for the location and urban-economic development of capital cities to the cities of Columbus, Des Moines, and Frankfort, and discusses the current status of selected former capitals. The book concludes with a consideration of the role of state capitals today as "symbols of American democracy."

The narrative is well supported with factual detail. I was struck by some similarities to research by the mid-twentieth-century urban and cultural geographers Chauncy Harris and Wilbur Zelinsky, each of whom conducted research using cities or places as units of analysis, creating classifications and typologies based on socio-demographic, economic, and cultural factors. Curiously, neither of these researchers are listed in this book's index. However, quantitative analysis with mathematical models, typical of both Harris and Zelinsky, does not feature prominently in the discourse provided by Montès.

Having carefully read this monograph, I can say that I learned some things about state capitals (and capitols) that I had not previously known. However, I did not come away convinced that the subject was truly worthy of this level of scholarly investigation. The explanatory model developed in the later chapters and examined through three case studies seems contrived as well as overly complex. The vignettes of each of these capital cities, on the other hand, could stand on their own, losing little of their substance in the model's absence.

American Capitals is well illustrated, with photographs, tables, occasional diagrams, and a few maps. The end matter includes appendices with demographic and historical tables, a state-by-state chronology of colonial, territorial, and state capitals, and finally, notes, references, and an index.

In the final analysis, while I'm still not sure that the topic of state capitals in the US is worthy of a full-length book treatment, I am convinced that Christian Montès has examined them from almost every conceivable social scientific perspective, save perhaps scientific qualitative approaches with focus groups, participant observation research, or multivariable modeling. While his writing is informative and in some sections quite engaging, the reader sometimes gets lost in a mire of technical details. Given that no one had ever attempted to write a book like this previously, American Capitals is likely to be the go-to source for details about the geography of the capitals of US states for many years to come.

This monograph is a recent addition to one of the most venerable scholarly monograph series in North American academic geography. I was pleased to see this tradition from the University of Chicago continue, albeit with a lapse of eight years since the previous volume, and hope that more works are in the pipeline.

\section{MAKING SPATIAL DECISIONS USING GIS AND LIDAR: A WORKBOOK}

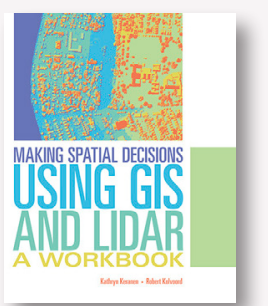

by Kathryn Keranen and Robert Kolvoord

Esri Press, 2016

216 pages. $\$ 79.99$, softcover.

ISBN: 978-1-58948-429-0

Review by: Greg March

Making Spatial Decisions Using GIS and Lidar: A Workbook, is the third book in the Making Spatial Decisions series. This tutorial is geared towards users who have basic GIS skills and want to learn how to integrate and analyze Light Detection and Ranging (lidar) data as part of a GIS project to solve problems and create high resolution maps. Below is the four-step workflow described in the book:

1. Define the problem or scenario.

2. Identify the deliverables needed to support decisions.

3. Document, set environments, and examine the data.

4. Perform analysis starting with a basemap. 